\title{
"Accept Me, or Else...": Disputed Overestimation of Social Competence Predicts Increases in Proactive Aggression
}

\author{
Bram Orobio de Castro • Mara Brendgen • \\ Herman Van Boxtel · Frank Vitaro · Linda Schaepers
}

Published online: 11 January 2007

(C) Springer Science+Business Media, LLC 2007

\begin{abstract}
It has been proposed that aggressive behavior may result from unrealistically positive self-evaluations that are disputed by others (Baumeister, Smart, \& Boden, 1996). The present three studies tested this proposition concurrently and longitudinally for the domain of self-perceived social competence (SPSC) in 3-6th grade children on two continents. Each study tested whether aggressive behavior is related to general overestimation of SPSC compared to competence as perceived by peers, or to disputed overestimation, that is, overestimation disputed through rejection by peers. Specificity of relations with reactively or proactively aggressive behavior patterns was assessed and the predictive value of overestimation to the development of these types of aggressive behavior was investigated. Concurrently, disputed overestimation explained more variance in aggressive behavior than general overestimation, and was uniquely related to proactive aggression. Longitudinally, disputed overestimation also uniquely predicted changes in proactive, not reactive aggression.
\end{abstract}

Keywords Self-perception · Social cognition · Peer relations $\cdot$ Aggressive behavior

B. Orobio de Castro $(\square) \cdot$ H. Van Boxtel $\cdot$ L. Schaepers Department of Developmental Psychology,

Utrecht University, The Netherlands

e-mail: b.castro@fss.uu.nl

M. Brendgen

Department of Psychology,

Universite du Quebec a Montreal, Canada

F. Vitaro

Research Unit on Children's Psychosocial Maladjustment,

University of Montreal, Canada
Several scholars (e.g., Bandura, 1997; Harter, 1983) have suggested that positive self-perceptions are characteristic of mental health and successful developmental adaptation. In concordance with this view, high levels of aggression have long been assumed to be related to negative self-evaluation. Based on this assumption, numerous prevention and intervention programs aim to bolster children's self-evaluation, expecting this will reduce or prevent aggressive behavior problems. However, numerous empirical studies have failed to show a consistent relation between negative selfevaluation and aggressive behavior (Baumeister, Smart, \& Boden, 1996). In children, research on this issue has primarily focused on self-perceived social competence (SPSC), because of the importance of social relations for the development of social competencies. As for negative self-perception in general, research on relations between SPSC and aggressive behavior has yielded indecisive and at times contradictory empirical findings (Baumeister et al., 1996; Salmivalli, 2001). This may be due to a number of factors.

The most fundamental issue seems that no clear theoretical rationale has been formulated why to expect low SPSC and aggressive behavior to be related. It has more or less implicitly been assumed that aggressive behavior may be a form of 'externalized' intra-psychological turmoil due to insecurity and dissatisfaction with oneself, but whether and how this mechanism operates has-as far as we know-not been made plausible. Recent approaches to the study of intra-psychological proximal antecedents of aggressive behavior include social information-processing and functional emotion approaches (e.g. Crick \& Dodge, 1994; Frijda, 1986; Lemerise \& Arsenio, 2000). From both these perspectives, it would seem unlikely that low SPSC would be related to aggressive behavior. From functionalist emotion theories (e.g. Frijda, 1986) one would expect low SPSC to lead to feelings of sadness, guilt or shame, which 
inhibit aggressive behavior rather than promote it. From this perspective, aggressive behavior would be more likely to result from feelings of anger, associated with negative evaluations of other's behaviors and a positive self-evaluation. Similarly, from a social information-processing perspective, highly aggressive children engaged in conflicts with peers have consistently been found to evaluate their own social behavior overly positively and to evaluate peer's behaviors overly negatively (e.g. Dodge, 1980; Lochman \& Dodge, 1998; Orobio de Castro, Veerman, Koops, Bosch, \& Monshouwer, 2002), whereas negative evaluation of own social competences has been found to be related to depression rather than to aggressive behavior (Quiggle, Garber, Panak, $\&$ Dodge, 1992). Thus, although studies in this field have predominantly tested low SPSC hypotheses, there is ample reason to formulate and test alternative hypotheses.

Another reason for the absence of relations between low SPSC and aggressive behavior may be that research has traditionally focused on individual differences in absolute levels of SPSC, whereas congruency between self-evaluation and evaluations made by the social environment may be more relevant than absolute negativity or positivity of selfevaluations (e.g. Brendgen, Vitaro, Turgeon, Poulin, \& Wanner, 2004; Salmivalli, 2001). As early as 1934, Mead (1934) suggested that self-evaluations may be derived from evaluations made by important others, the so-called 'looking glass self.' Adaptive functioning in many domains has been related to a certain degree of congruence between selfevaluation of behavior in a specific domain and the evaluation of that behavior by important others (although it remains unclear whether a slight positive bias may be more adaptive than complete congruence, see Taylor \& Brown, 1988). Thus, the absolute negativity or positivity of self-evaluations may be less relevant than their congruency with others' evaluations.

Aggressive behavior and disputed unrealistically high self-esteem

Building on the idea that congruency between SPSC and evaluation by others may be most relevant to social functioning, Baumeister et al. (1996) proposed that aggressive behavior does not result from absolute self-evaluation, but rather from self-evaluations that are unrealistically more positive than evaluations by others. These authors expect aggressive behavior to occur when an unrealistically positive self-evaluation is challenged by others. On such occasions aggressive behavior serves to silence or reprimand those disputing the overly positive self-evaluation. Thus, according to Baumeister et al., certain people do not attempt to attain congruency by lowering their self-evaluation, but by trying to force others to heighten their evaluation. Considerable support for this hypothesis has been found in adults, pre- dominantly in studies with college students (Bushman \& Baumeister, 1999, 2002).

In children, congruency between self- and otherevaluations has predominantly been studied in the context of self-perceived social competence (SPSC). Age-group comparisons show that, although most young children tend to overestimate their own social competence with peers, self-perceptions generally become more 'accurate' over the course of middle childhood (Hymel, Franke, \& Freigang, 1985). Nevertheless, some children continue to overestimate their social competence compared to their peers' view, and this lack of congruency should, according to Baumeister et al. (1996), negatively impact on children's social behavior. High levels of aggressive behavior should be expected for children with unrealistically high SPSC in comparison to their actual social competence according to peers.

This hypothesis was tested in several studies concerning general overestimation of SPSC compared to competence perceived by peers (Brendgen et al., 2004; David and Kistner, 2000; Hughes, Cavell, \& Grossman, 1997). In these studies overestimation was operationalized by regressing SPSC on sociometric ratings of social preference according to peers and using the resulting residual scores as indicators of overestimation of social competence. Cross-sectionally, a linear relation was found between overestimation of SPSC, on the one hand, and overt and relational aggression, on the other hand (David \& Kistner, 2000). Longitudinally, overestimation was found to predict increases in aggressive behavior and decreases in self-reported depressive feelings over a sixmonth period (Brendgen et al., 2004).

Even though findings concerning general overestimation of SPSC seem to support the disputed positive self-evaluation hypothesis, conceptually there appears to be a difference between general overestimation as studied and disputed positive self-evaluation as formulated by Baumeister et al. (1996). Both concern discrepancies between more favorable self-evaluation and less favorable evaluation by others, but the first concerns the extent to which the two evaluations differ, regardless of their absolute levels, whereas the latter specifies that evaluations by others should not only be less favorable than self-evaluations, but should actually be negative. It would seem that the extent to which others evaluations invoke aggression does not only depend on the degree to which they differ from one's own evaluation, but also on the extent to which they are actively negative. A highly positive self-view may not be threatened by generally positive evaluations by others, even if these are more modest than one's own evaluation. Yet the same amount of discrepancy may be an affront if evaluations by others are clearly negative.

From these considerations we derived the disputed overestimation hypothesis (see also Van Boxtel, Orobio de Castro, \& Goossens, 2004) that relations between 
overestimation and aggressive behavior should be specific to children who are rejected by other children. That is, even if similar degrees of overestimation were found for rejected and non-rejected children, relations with aggressive behavior would only be expected for rejected children, because only these children experience actual threats to their self-evaluation due to the truly negative regard from their peers. For these children, disputed overestimation might either provoke reactive aggression to fend off the threat rejection forms to their self-regard, or proactive aggression as a means to coerce other children into less rejecting behavior.

The aim of the present studies was to test the tenability of the general overestimation and disputed overestimation hypotheses formulated above for the domain of children's social relations with peers by examining concurrent and longitudinal links between SPSC, rejection by peers, and reactively and proactively aggressive behavior. Three studies were conducted. The first study concerned concurrent tests of the hypotheses with regard to physical aggression. The second study concerned the specific concurrent relations of general and disputed overestimation with reactive and proactive aggression. The third study tested concurrent and longitudinal relations of general and disputed overestimation with reactive and proactive aggression. The third study was conducted in Canada and thereby also served as an international validation of findings from the first two studies, which were both conducted in the Netherlands.

\section{Study 1: Goals}

The goal of Study 1 was to test whether physical aggression is related to general overestimation of SPSC (compared to peerrated actual social preference), or to disputed overestimation, i.e. overestimation in combination with rejection by peers.

\section{Study 1: Method}

Participants

Participants were recruited from eight grade 5 and 6 classrooms in four elementary schools that attract middle class children, located in average-sized Dutch cities. Because only very few children were non-Caucasian, ethnicity was not assessed. Parental consent was solicited by means of a letter to the parents at the start of the project. Consent was not obtained for only one or two pupils per class at most, resulting in participation rates of over $90 \%$ per class. All children in the participating classrooms could be nominated in the sociometric assessment (see Measures). Sociometric data were collected for 189 eight to twelve year-old children (93 boys, 96 girls), with a mean age of 9.7 years, $S D=1.7$.

Procedure

Measures were completed at school during regular class hours. Graduate students in developmental psychology read the instructions out loud and made sure that each participant understood the instructions. It was explained that there were no right or wrong answers and that all answers would be treated confidentially and anonymously.

Measures

\section{Peer-perceived social competence}

Children's Peer-perceived social competence was assessed with a sociometric nomination procedure. A list of the names of all children in a given class was handed out to the participants. Children were then asked to nominate three children of the same or opposite sex from this list that they most liked to play with (positive nominations) and three other children of the same or opposite sex from this list that they least liked to play with (negative nominations). From these nominations, a continuous social preference and a dichotomous rejected status-group membership variable were calculated for each participant following Coie, Dodge, and Coppotelli (1982). Social preference was calculated for each participant by subtracting the number of received negative nominations ( $z$-standardized within each classroom) from the number of received positive nominations (also z-standardized within each classroom). A dichotomous rejected sociometric status variable was then created to distinguish rejected children, i.e., those with a social preference score of $1 \mathrm{SD}$ below the mean or less ( $n=28$ or $15 \%$ ) from all others. This dichotomous variable was used in subsequent analyses as the moderator variable. ${ }^{1}$

\section{Aggressive behavior.}

Physical aggression was assessed with the same sociometric nomination procedure. From a questionnaire of 16 items (using short behavioral descriptions translated from Coie et al., 1982), the item concerning fights with peers was used. For this item, participants were asked to nominate up to three classmates who best fit the description "Some classmates

\footnotetext{
${ }^{1}$ To test whether data reduction from the continuous social preference variable to the dichotomous rejection variable influenced the findings, all analyses reported for the three studies were also conducted using the social preference variables instead of the rejection variables. When doing so, all findings essentially remained the same. For clarity of exposure we only discuss analyses conducted with the rejection variables here. Results of analyses with the social-preference variables are available from the first author on request.
} 
often fight. They say mean things to other classmates, or push or hit them". The standardized summed score of the received nominations for this item was used.

\section{Self-perceived social competence.}

Self-perceived social competence (SPSC) was assessed with the Social Acceptance subscale of the Dutch version of Harter's Self-Perception Profile for Children (Harter, 1985; for the Dutch version see Veerman, Straathof, Treffers, Van Den Bergh, \& Ten Brink, 1987). This scale consists of six items and includes positively as well as negatively worded items, for example "some children have many friends, other children have few friends". Children were first asked to choose which statement resembled them most and then indicated whether they found the chosen statement to be true a little or a lot. Subsequently, the items were rescored on a scale of 1 to 4 . An average total Self-perceived Social Acceptance scale was computed such that a higher total score reflected a more positive self-image. Reliability for the Dutch version of this subscale is acceptable (internal consistency $>.70$; testretest reliability is .68; Veerman et al., 1987). Cronbach's alpha for the total self-perceived social acceptance scale in the present sample was $.76, M=3.00, S D=.64$, range from 1.3 to 4.

\section{Overestimation.}

To operationalize children's overestimation (and underestimation) of their social competence, we followed the strategy adopted in previous studies (e.g., Brendgen et al., 2004; Cole, Martin, Peeke, Seroczynski, \& Fier, 1999; Cole, Martin, Peeke, Seroczynski, \& Hoffman, 1998; David \& Kistner, 2000; Hoffman, Cole, Martin, Tram, \& Seroczynski, 2000; McGrath \& Repetti, 2002). Specifically, we computed a standardized residual score by regressing children's SPSC on their peer-perceived social preference score. The strategy of a residual difference score was chosen over a simple difference score because peer-perceived social competence and SPSC were not based on the same measure, which makes it inherently difficult to establish a base of comparison between the two variables. This problem is circumvented by using a residual score, which reflects the portion of SPSC that cannot be predicted from peer-perceived social competence. As such, a standardized residual score above zero represents a more positive evaluation of social competence from a child's own perspective than would be expected based on his peer-perceived social competence score. In contrast, a residual score below zero represents a more negative evaluation from a child's own perspective than would be expected from his peer-perceived social competence score.

\section{Study 1: Results}

\section{Preliminary analyses}

Rejected children $(M=1.16, S D=1.49)$ where involved in more fights than their peers $(M=-.19, S D=.70)$, $t(1,28.7)=5.85, p<.001$. To rule out the possibility that overestimation would only be related to aggression in rejected children due to higher degrees of overestimation in the rejected group, mean overestimation scores for rejected $(M=.04, S D=1.14)$ and non-rejected children $(M=-.01, S D=.98)$ were compared. The groups did not differ in regard to overestimation nor in regard to withingroup variance of overestimation.

General and disputed overestimation

To test the general and disputed overestimation hypotheses, a hierarchical regression analysis was conducted with fight reputation as dependent variable. Sex and rejection were entered on the first step of the analysis. Sex was coded such that 0 indicated girls and 1 indicated boys. Rejection was coded such that 0 indicated non-rejected children and 1 indicated rejected children. Overestimation was entered in the second step. A multiplicative interaction term of the standardized overestimation variable $\times$ rejection was added in the third step. To facilitate interpretation and to avoid multicollinearity problems, all continuous variables were $z$-standardized prior to creating the interaction term (Holmbeck, 2002). The general overestimation hypothesis would predict a significant contribution of the overestimation variable on the second step. The disputed overestimation hypothesis would predict that inclusion of the interaction term on the third step of the analysis significantly increases explained variance. If-after inclusion of the interaction term-the main effect of overestimation is nonsignificant, only the disputed overestimation hypothesis but not the general overestimation hypothesis would be supported. The results for these analyses are shown in Table 1 . The variance inflation indicators showed that multicollinearity was no problem in the analysis.

In line with the general overestimation hypothesis, overestimation was positively related to fights when included on the second step of the analysis, $b=.18, t=3.12, p=.002$. However, the general effect of overestimation became nonsignificant when the significant interaction term was added to the model. To interpret the nature of the interaction, we followed the strategy recommended by Holmbeck (2002) for dichotomous moderator variables. Specifically, the main effect of overestimation for nonrejected children was already provided on the last step of the regression analysis, which included the interaction term between overestimation and rejection. The rejection variable was then recoded such that 0 
Table 1 Study 1 Hierarchical regression analyses of fight reputation on sex, rejected social status, general overestimation, and disputed overestimation

\begin{tabular}{llllll}
\hline & Predictor & $\beta$ & $t$ & $F$ change $(d f)$ & $R^{2}$ change \\
\hline Step 1 & Sex & $.43^{* * *}$ & 7.38 & $61.73(2,178)$ & $.41^{* * *}$ \\
& Rejected Status vs. Others & $.45^{* * *}$ & 7.71 & & \\
Step 2 & Overestimation & $.18^{* *}$ & 3.12 & $9.72(1,177)$ & $.03^{* *}$ \\
Step 3 & Rejected Status $\times$ & $.27^{* * *}$ & 4.90 & $24.03(1,176)$ & $.07^{* * *}$ \\
& Overestimation & & & & \\
\hline
\end{tabular}

Note. Sex refers to girls as reference group. Rejected status refers to non-rejected children as reference group. The Rejected Status $\times$ Overestimation interaction term refers to the multiplicative interaction between rejected status and standardized overestimation.

${ }^{*} p<.05$.

${ }^{* *} p<.01$.

$* * * p<.001$.

indicated rejected children and 1 indicated nonrejected children and a new interaction term was calculated between overestimation and the recoded rejection variable. The regression analysis was then repeated using these new variables. The results from these two different regression analyses revealed that, for rejected children, overestimation significantly predicted fights over and above sex, $\beta=.73, p<.001$. For non-rejected children, no effect of overestimation on fights was found, $\beta=.08, p=.197$. Thus, in line with the disputed overestimation hypothesis, a positive relation between overestimation and aggression was only found within the rejected group. The slopes of these regressions are depicted in Fig. 1.

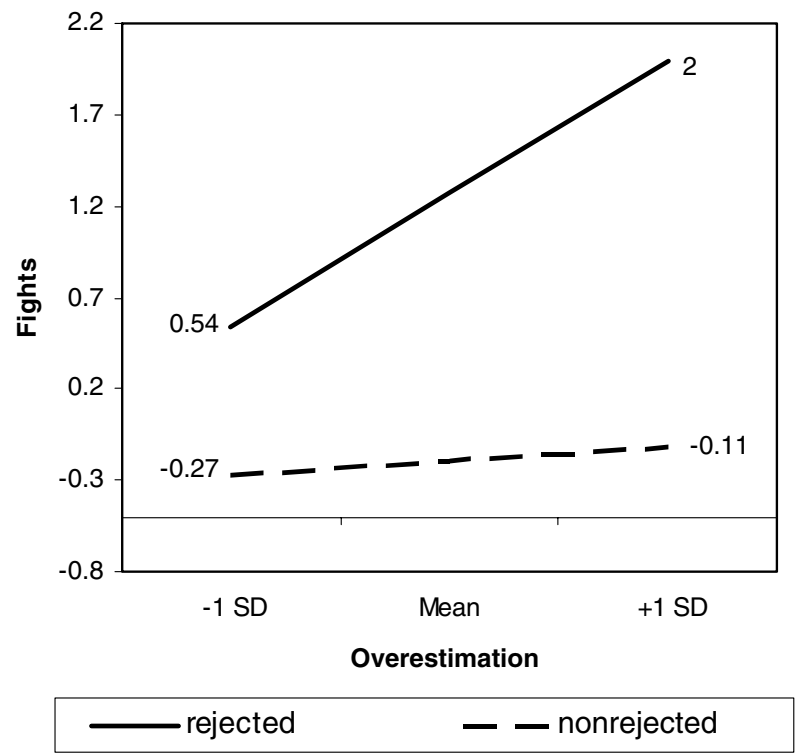

Fig. 1 Study 1 slopes for regression of aggression on overestimation in the rejected and the nonrejected group

\section{Study 1: Discussion}

Overestimation of social competence was found to be associated with fights, specifically in rejected children. The disputed overestimation hypothesis was supported and explained more variance in aggressive behavior than the general overestimation hypothesis. In line with Baumeister and colleagues' theorizing, the present findings can be interpreted as preliminary evidence for the proposition that rejected children act aggressively when their relatively favorable selfevaluation is threatened or disputed by peers who reject them. However, the present study only concerned fighting. To assess to which type of aggression the disputed overestimation hypothesis applies, study two addressed disputed overestimation in relation to reactive and proactive aggression, two specific kinds of aggressive behavior with distinct underlying goals and distinctive putative causes.

\section{Study 2: Goals}

The main goal of Study 2 was to test whether disputed overestimation is specifically related to reactive or proactive aggression. Reactive aggression is angry, "hot-blooded" behavior in reaction to a presumed threat, whereas proactive aggression is planned, instrumental and "cold blooded" behavior (Dodge, 1991). Research indicates that these kinds of aggression are related to different precursors, correlates, and prognoses (Dodge, Lochman, Harnish, Bates, \& Pettit, 1997; Vitaro, Brendgen, \& Tremblay, 2002). In theory, specific relations of reactive and proactive aggression with overestimation seem plausible. At first sight, Baumeister et al.'s descriptions of aggressive reactions to disputed overestimation appear reactive in nature. As the phrase "threatened egotism" implies, they concern defensive reactions to perceived threats. Aggressive reactions to perceived threats are 
by definition reactive and tendencies to attribute hostile intent to others have been found to be more strongly associated with reactive than proactive aggression (Crick \& Dodge, 1996; Orobio de Castro, Merk, Koops, Veerman, \& Bosch, 2005). However, reactive aggression also has been related to depression (Vitaro et al., 2002), which is typically associated with an underestimation instead of an overestimation of social competence (Brendgen, Vitaro, Turgeon, \& Poulin, 2002; Brendgen et al., 2004). Furthermore, one may question whether overestimation would not diminish when peer's behaviors are overinterpreted as threatening or hostile, as is the case in reactive aggression. According to Mead's congruency hypothesis (1934), such sensitivity to (perceived) negative peer evaluation would result in decreased SPSC to a more realistic level.

In contrast, proactive aggression is not associated with depressed affect (Vitaro et al., 2002). It is associated with positive outcome expectancies for aggression and appreciation of instrumental over social goals (Dodge et al., 1997). Proactive aggression may be associated with attempts to maintain a dominant social position one feels entitled to. Along this line of thought, self-perceived social competence may indicate that one feels entitled to a corresponding social position in class, with proactive aggression as an adequate means to claim that position if need be. If so, proactive aggression may serve as a self-perceived coercive competence that helps maintain a social position with peers who might be openly rejecting if proactive aggression were not used. Although speculative, this point of view fits highly aggressive boys' self-reported reasons for their proactively aggressive behavior in terms of obligations to command respect or to show others their place (Orobio de Castro, 2004). To resolve this issue, the present study aimed to test the unique relations of general overestimation and of disputed overestimation to reactive and proactive aggression, respectively. Furthermore, the study served to replicate the findings from Study 1 in a larger sample, using multiple aggression nominations rather than the single item used in Study 1.

\section{Study 2: Method}

Participants

Participants were recruited from grades 3 to 5 of five elementary schools in an average-sized Dutch city with the procedure described for Study 1, again resulting in participation rates of over $90 \%$ per class. Sociometric data were collected for 301 eight to eleven year-old children (159 girls), with a mean age of $9.8, S D=.95$. None of these children had also participated in Study 1.
Measures

\section{Reactive and proactive aggression.}

Reactive and proactive aggression were assessed through peer nominations. For each of 12 behavior descriptions concerning reactive and proactive aggression, participants were asked to nominate three classmates. The items were derived from the Teacher Rating of Aggression (Dodge \& Coie, 1987) and the Reactive and Proactive Aggression Questionnaire (RPAQ; Kempes, Matthys, Maassen, Van Goozen, \& Van Engeland, in press). Examples of items for reactive and proactive aggressions, respectively, are "This classmate overreacts angrily to accidents" and "This classmate gets others to gang up on peers." Nominations for each type of aggression were standardized within classrooms and summed, resulting in highly reliable reactive and proactive aggression scales, with respective alpha's of .97 and .90 . Reactive and proactive aggression were strongly correlated, $r=.81$.

Self-perceived and peer-perceived social competence, and overestimation were assessed as in Study 1. Cronbach's alpha for SPSC in the present sample was .72, $M=2.98$, $S D=.66$, ranging from 1 to 4 . Forty-nine children (16\%) were rejected.

\section{Study 2: Results}

Rejected children where more reactively aggressive than their peers $(M=1.53, S D=1.24$ and $M=-.27$, $S D=.65$, respectively), $t(1,52.8)=9.91, p<.001$, and more proactively aggressive than their peers $(M=1.47$, $S D=1.28$ and $M=-.26, S D=.67$, respectively), $t(1,52.6)=9.19, p<.001$. Mean overestimation scores for rejected $(M=.04, S D=1.25)$ and non-rejected children $(M=-.01, S D=.95)$ did not differ, $t(1,54.8)=.25$, n.s. Variance in reactive and proactive aggression was larger in the rejected than in the nonrejected group. Variance in overestimation did not differ between groups.

Hierarchical regression analyses of reactive/proactive aggression on sex, rejected status, overestimation and their interaction were conducted as explained for Study 1. Again, sex was coded such that 0 indicated girls and 1 indicated boys. Rejection was coded such that 0 indicated non-rejected children and 1 indicated rejected children. In addition, the respective "other" type of aggression was included as a control variable on the first step of these analyses. The results for these analyses are summarized in Table 2 . Again, all continuous variables were $z$-standardized prior to creating the interaction term to facilitate interpretation and to avoid multicollinearity problems, (Holmbeck, 2002). The variance inflation indicator showed multicollinearity was no problem in the analysis. No variance in reactive aggression 
Table 2 Study 2 Hierarchical regression of reactive/proactive aggression on proactive/reactive aggression, sex, rejected status, overestimation and their interaction

\begin{tabular}{|c|c|c|c|c|c|}
\hline & Predictor & $\beta$ & $t$ & $F$ change $(d f)$ & $R^{2}$ change \\
\hline \multicolumn{6}{|c|}{ Set A: Prediction to Proactive Aggression } \\
\hline \multirow[t]{3}{*}{ Step 1} & Sex & $.20^{* * *}$ & 6.04 & \multirow[t]{3}{*}{$244.9(3,297)$} & \multirow[t]{3}{*}{$.71^{* * *}$} \\
\hline & Reactive aggression & $.68^{* * *}$ & 16.10 & & \\
\hline & Rejected status vs. others & $.13^{* *}$ & 3.38 & & \\
\hline Step 2 & Overestimation & .08 & $2.57 *$ & $6.60(1,296)$ & $.01 *$ \\
\hline Step 3 & $\begin{array}{l}\text { Rejected Status } \times \\
\text { Overestimation }\end{array}$ & $.11^{* *}$ & 3.11 & $9.65(1,295)$ & $.01^{* *}$ \\
\hline \multicolumn{6}{|c|}{ Set B: Prediction to Reactive Aggression } \\
\hline \multirow[t]{3}{*}{ Step 1} & Sex & .06 & 1.76 & \multirow[t]{3}{*}{$242.1(3,297)$} & \multirow[t]{3}{*}{$.71^{* * *}$} \\
\hline & Proactive aggression & $.69^{* * *}$ & 16.28 & & \\
\hline & Rejected status vs. others & $.25^{* * *}$ & 6.24 & & \\
\hline Step 2 & Overestimation & -.04 & 1.34 & $1.79(1,296)$ & .00 \\
\hline Step 3 & $\begin{array}{l}\text { Rejected status } \times \\
\text { overestimation }\end{array}$ & -.03 & .87 & $.75(1,295)$ & .00 \\
\hline
\end{tabular}

Note. Sex refers to girls as reference group. Rejected status refers to non-rejected children as reference group. The Rejected Status $\times$ Overestimation interaction term refers to the multiplicative interaction between rejected status and standardized overestimation.

${ }^{*} p<.05$.

${ }^{* *} p<.01$

${ }^{* * *} p<.001$.

was explained by overestimation or the interaction term. However, the interaction of overestimation and rejection explained a signification portion of the variance of proactive aggression over and above reactive aggression, rejection, sex, and overestimation. The nature of the interaction effect was again probed following the recommendation by Holmbeck (2002) for dichotomous moderator variables. The results revealed that, for rejected children, overestimation significantly predicted proactive aggression over and above sex and reactive aggression, $\beta=.24, p<.001$. For nonrejected children, no effect of overestimation on proactive aggression was found, $\beta=.03, p=.418$. Thus, positive relations between overestimation and aggression were found specifically for the rejected group, and uniquely for proactive aggression.

\section{Study 2: Discussion}

Study 2 replicated the support for the disputed overestimation hypothesis found in Study 1 by showing a relation between aggressive behavior and overestimation specifically for rejected children. Moreover, this relation was found to be specific to proactive aggression, suggesting that some rejected children who overestimate their social competence may try to coerce others into showing them the acceptance they believe to deserve. However, an alternative explanation for the specific relation between overestimation and proac- tive aggression found in Study 2 may be that it is partly due to informant bias, as both rejection and aggressive behavior were assessed by peers. A more stringent test of the disputed overestimation hypothesis would therefore include assessment of social status and aggressive behavior by different informants. Furthermore, to understand the dynamics of the relations found between proactive aggression, rejection, and overestimation, it would be important to study these relations longitudinally. Longitudinal studies may assess the proposed directionality of this effect by testing whether overestimation in rejected children is uniquely predictive of increases in proactive aggression. Such assessment was provided in Study 3 .

\section{Study 3: Goals}

Studies 1 and 2 supported the disputed overestimation hypothesis cross-sectionally in Dutch samples. Study 3 extended these findings with longitudinal data and included parent assessment of reactive and proactive aggression, in a different cultural context. The aims of Study 3 were to replicate the basic findings of the first two Dutch studies in a different cultural context, to assess the directionality of the effect between disputed overestimation and proactive aggression longitudinally, and to test whether these results hold even when no shared source variance is present in the predictor and criterion variables. 


\section{Study 3: Method}

Participants

Participants of the present study were 231 Caucasian, French-speaking children (110 girls) of average socioeconomic status from a small city in Northwestern Québec, Canada, who were followed over a three-year period from grades 4 through 6 . Participants' average age was 10 years 2 months in grade 4 . At least $90 \%$ of all the students in the targeted classrooms participated in the study. Those who did not participate did not receive parental permission or were absent from school on the day of data collection. Sixty-six (28\%) of children were lost between grades 4 and 6, because they either had moved to another city or because their mothers refused to further participate in the study. As a result, the final sample size for analyses was $n=165$ ( 80 girls). Those who were lost differed from those who were retained in the study in that the former were less accepted by their peers in grade 4 than were the latter, as indicated by a lower social preference score, $t(229)=-2.85, p<.01$ (see description of measures below). Parental permission was obtained each year for each participant. The research questions and instruments were approved by the IRB and the school board administrators.

\section{Measures}

\section{Self-perceived social competence.}

When children were 10 years old, their SPSC was assessed with the 6-item social acceptance subscale of the SelfPerception Profile for Children (SPPC; Harter, 1985) also used in Studies 1 and 2. The French version of the instrument has shown excellent internal consistency, test-retest reliability, and factorial and convergent validity with 3rd through 6th graders (Boivin, Vitaro, \& Gagnon, 1992). Cronbach's alpha for the SPSC scale in the present sample was .76, $M=3.02$, $S D=.63$, range from 1 to 4.

\section{Peer-perceived social competence and overestimation of social competence}

Also at age 10 years, children's Peer-Perceived Social Competence was assessed with the same sociometric procedures used in the previous studies, resulting in 19 children with rejected status (11.5\%). Overestimation was operationalized the same way as in the previous studies.

\section{Proactive and reactive aggression.}

When children were aged 10 through 12 years, mothers completed the three reactive and three proactive aggressiveness items used by Dodge and Coie (1987). Given that these items were imbedded in the Social Behavior Questionnaire (Tremblay et al., 1991) the three-unit response scale of the SBQ items was also used with the proactive and reactive items instead of the original 5-unit scale. The three-unit anchors were: does not apply (scored 0), applies sometimes (scored 1), applies often (scored 2). Means and standard deviations for reactive aggression at ages 10, 11, and 12, respectively, were $1.60(S D=1.27), 1.22(S D=1.20)$, and $1.03(S D=1.23)$; for proactive aggressiveness, the means and standard deviations at ages 10,11 , and 12 , respectively, were: $0.65(S D=0.92), 0.42(S D=0.86)$, and 0.52 $(S D=0.98)$. Internal consistency was high for the proactive aggression variables (alphas from .81 to .83 for ages 10 through 12) and reactive aggression variables (alphas $=.85$, .84 , and .81 , for ages 10,11 , and 12 , respectively). Stability coefficients and cross-correlations for proactive aggression and reactive aggression over the assessed three-year period are given in Table 3. For reactive and proactive aggression, respectively, an average score was computed across ages 11 and 12 to maximize variance of the aggression scores. These average scores were then used as dependent variables in the subsequent analyses. Children for whom mother ratings were available at age 11 but not at age $12(n=28)$, only the age 11 ratings were used.

Table 3 Stability coefficients and cross-correlations of reactive and proactive aggression across ages 10, 11, and 12 years

\begin{tabular}{|c|c|c|c|c|c|c|}
\hline & A & $\mathrm{B}$ & $\mathrm{C}$ & $\mathrm{D}$ & $\mathrm{E}$ & $\mathrm{F}$ \\
\hline A. Age 10 Reactive aggression & 1.00 & & & & & \\
\hline B. Age 11 Reactive aggression & $.63^{* * *}$ & 1.00 & & & & \\
\hline C. Age 12 Reactive aggression & $.58^{* * *}$ & $.55^{* * *}$ & 1.00 & & & \\
\hline D. Age 10 Proactive aggression & $.50^{* * *}$ & $.38^{* * *}$ & $.33^{* * *}$ & 1.00 & & \\
\hline E. Age 11 Proactive aggression & $.43^{* * *}$ & $.54^{* * *}$ & $.46^{* * *}$ & $.49^{* * *}$ & 1.00 & \\
\hline F. Age 12 Proactive aggression & $.41^{* * *}$ & $.38^{* * *}$ & $.56^{* * *}$ & $.36^{* * *}$ & $.47^{* * *}$ & 1.00 \\
\hline
\end{tabular}


Table 4 Zero-order correlations of the variables used in the analyses of Study 3

\begin{tabular}{|c|c|c|c|c|c|c|c|}
\hline & A & $\mathrm{B}$ & $\mathrm{C}$ & $\mathrm{D}$ & $\mathrm{E}$ & $\mathrm{F}$ & G \\
\hline A. $\operatorname{Sex}$ & 1.00 & & & & & & \\
\hline B. Age 10 Reactive aggression & $.18^{*}$ & 1.00 & & & & & \\
\hline C. Age 10 Proactive aggression & $.20^{* *}$ & $.50^{* * *}$ & 1.00 & & & & \\
\hline D. Rejected Status vs. Others & .05 & .07 & .14 & 1.00 & & & \\
\hline E. Overestimation & .11 & -.06 & -.01 & -.01 & 1.00 & & \\
\hline F. Age 11-12 Reactive aggression & $.19^{*}$ & $.66^{* * *}$ & $.40^{* * *}$ & $.15^{*}$ & .09 & 1.00 & \\
\hline G. Age 11-12 Proactive aggression & .11 & $.46^{* * *}$ & $.48^{* * *}$ & .12 & .08 & $.58^{* * *}$ & 1.00 \\
\hline
\end{tabular}

Notes. Sex refers to girls as reference group. Rejected status refers to non-rejected children as reference group.

${ }^{*} p<.05$.

${ }^{* *} p<.01$.

${ }^{* * *} p<.001$.

Procedure

All instruments were administered in French. The semantic accuracy of translated instruments was verified by bilingual native speakers of French.

\section{Study 3: Results}

Children who were rejected at 10 years of age were not significantly more reactively aggressive than nonrejected children according to mothers at age 11-12, although the former showed greater variability in regard to reactive aggression than the latter, $M=1.63, S D=1.37$, and $M=1.11$, $S D=1.07$, respectively, $t(1,20.93)=1.61, n s$. Rejected children were also not rated as being more proactively aggressive at ages 11-12, despite showing greater variability in regard to proactive aggression, than nonrejected children at age $11-12, M=.82, S D=1.23$, and $M=.48, S D=.81$, respectively, $t(1,20.11)=1.17, n s$. In addition, children who were rejected did not differ from nonrejected children in regard to their level of overestimation of social competence, although the former showed greater variability in regard to overestimation than the latter, $M=.02, S D=1.33$, and $M=.06, S D=.96$, respectively, $t(1,20.53)=.14, n s$.

To test the unique predictive value of disputed overestimation to change in proactive aggression, two separate hierarchical linear regression analyses were conducted to predict proactive aggression and reactive aggression, respectively, across ages 11 and 12 years. Zero-order correlations between the included variables are reported in Table 4. In the analysis predicting to proactive aggression, the following predictors were included on the first step: sex, proactive aggression at age 10, average reactive aggression across ages 11 and 12, and the dichotomous variable indicating rejected vs. nonrejected peer status. Again, sex was coded such that 0 indicated girls and 1 indicated boys. Rejection was coded such that 0 indicated non-rejected children and 1 indicated rejected children. On the second step, overestimation of so- cial competence was entered. On the third step, an interaction term between the dichotomous peer status variable and overestimation of social competence was added to the model. The corresponding procedure was used to predict the average reactive aggression score across ages 11 and 12. As in the previous studies, all continuous variables were $z$-standardized prior to creating the interaction term. The tolerance and variance inflation indicators showed that multicollinearity was not a problem in the two sets of analyses. The results for these analyses are provided in Table 5.

For proactive aggression, apart from the auto-correlation with the age 10 value of this variable and the effect of reactive aggression at ages 11 through 12, no other variable had a significant main effect in predicting proactive aggression at ages 11 through 12 . There was, however, a significant interaction effect between rejected status and children' overestimation of social competence. Probing of the interaction following the procedure recommended by Holmbeck (2002) revealed that overestimation was related to a significant increase in proactive aggression, but only for rejected children, beta $=.41$, $p<.001$. For nonrejected children, overestimation was unrelated to change in proactive aggression, beta $=-.05$, ns. In contrast to these findings, the analysis predicting to reactive aggression revealed no significant effect of overestimation of social competence, either for rejected or nonrejected children.

\section{Study 3: Discussion}

The findings from Study 3 support the results from the previous two studies, namely that overestimation of social competence is related to aggressive behavior, specifically to proactive aggression and specifically in rejected children. Moreover, the findings from Study 3 show that this link holds longitudinally over a 3-year time frame. 
Table 5 Study 3: Hierarchical regression analyses predicting to proactive aggression and reactive aggression at ages 11-12 years

\begin{tabular}{|c|c|c|c|c|c|}
\hline & Predictor & $\beta$ & $t$ & $F$ change $(d f)$ & $R^{2}$ change \\
\hline \multicolumn{6}{|c|}{ Set A: Prediction to Proactive Aggression at Age 11-12 } \\
\hline \multirow[t]{4}{*}{ Step 1} & Sex & .04 & 0.58 & $28.19(4,160)$ & $.41^{* * *}$ \\
\hline & Age 10 Proactive Aggression & $.31^{* * *}$ & 4.55 & & \\
\hline & Age 11-12 Reactive Aggression & $.46^{* * *}$ & 6.93 & & \\
\hline & Rejected Status vs. Others & .02 & 0.24 & & \\
\hline Step 2 & Overestimation & .04 & 0.71 & $0.50(1,159)$ & .00 \\
\hline Step 3 & Rejected Status $\times$ Overestimation & $.20^{* *}$ & 3.02 & $9.11(1,158)$ & $.03^{* *}$ \\
\hline \multicolumn{6}{|c|}{ Set B: Prediction to Reactive Aggression at Age 11-12 } \\
\hline \multirow[t]{4}{*}{ Step 1} & Sex & .06 & 1.06 & $47.08(4,160)$ & $.54^{* * *}$ \\
\hline & Age 10 Reactive Aggression & $.49^{* * *}$ & 7.80 & & \\
\hline & Age 11-12 Proactive Aggression & $.34^{* * *}$ & 5.56 & & \\
\hline & Rejected Status vs. Others & .07 & 1.34 & & \\
\hline Step 2 & Overestimation & .09 & 1.67 & $2.80(1,159)$ & .01 \\
\hline Step 3 & Rejected Status $\times$ Overestimation & -.10 & -1.58 & $2.51(1,158)$ & .01 \\
\hline
\end{tabular}

Note. Sex refers to girls as reference group. Rejected status refers to non-rejected children as reference group. The Rejected Status $\times$ Overestimation interaction term refers to the multiplicative interaction between rejected status and standardized overestimation.

${ }^{*} p<.05$.

${ }^{* *} p<.01$

${ }^{* * *} p<.001$.

\section{General discussion}

Three studies were conducted to test whether aggressive behavior is related to (a) general overestimation of SPSC compared to social competence as perceived by peers, or to (b) disputed overestimation, that is, overestimation in combination with rejection by peers. Findings from all three studies consistently supported the latter hypothesis by showing that aggressive behavior is related to high SPSC compared to peer-perceived social competence specifically in rejected children. Concurrently, disputed overestimation explained more variance in aggressive behavior than general overestimation, and was specifically related to proactive but not to reactive aggression. Longitudinally, disputed overestimation also uniquely predicted changes in proactive, not reactive aggression. Overall, support for the disputed overestimation hypothesis seems robust, given that these studies were conducted with children on two continents, using different aggression measures and different informants.

In line with Baumeister and colleagues' (1996) theorizing, the present findings could be interpreted as evidence for the proposition that rejected children with high SPSC act aggressively if their relatively favorable self-evaluation is not shared by peers who reject them. From the child's perspective it may seem logical to aggressively claim the social status he or she believes to be entitled to. This aggressive behavior may in turn exacerbate rejection by peers, leading to cycles of escalating behavioral interactions between the aggressive child and his or her peer group. However, the present study leaves many steps in this proposed chain of events unexplored. In theory, aggressive-rejected children fight when they experience a discrepancy between their own positive appraisal of their social behavior and other children's negative appraisal of their behavior, which they may believe to be unjust. Although the present findings are in line with this theory, they do not demonstrate the actual process the theory proposes. From the present findings, we cannot tell whether overestimating aggressive-rejected children themselves are aware that many peers dislike them, even though this would be a requirement for the discrepancy-aggression process to occur. Future studies may attempt to clarify the actual processes responsible for the established relation between proactive aggression, overestimation, and rejection. By observing children in actual (staged) conflict situations while inquiring about their own perceptions of their behavior as well as peers' perceptions in this regard (e.g. Lochman \& Dodge, 1998), relations between children's observed behavior, self-reported social information processing, and overestimation of their social competence may be tested validly in 'real time.'

Reactive and proactive aggression were quite strongly correlated in the present studies, as has generally been found in the literature (Vitaro et al., 2002). However, our assessments of reactive and proactive aggression may have provided inflated estimates of this correlation. Several recent studies suggest that reactive and proactive aggression are weakly or un-correlated if one takes into account that, on the presently used measures, informants may partly rate the 
extent to which participants are considered aggressive by giving highly aggressive children high scores on both reactive and proactive aggression items. This may have been particularly true for the peer assessments of aggression used in Study 2. Assessing the reactive or proactive functions of participants' aggression separately form the severity of this behavior results in uncorrelated dimensions of reactive and proactive aggression (Little, Henrich, Jones, \& Hawley, 2003; Polman \& Orobio de Castro, 2006). For the present studies, this might have resulted in more variance in proactive aggression to be explained independently from reactive aggression.

Disputed overestimation of own social competence explained substantial variance in proactive aggression among rejected children, but did-as predicted-not explain proactive aggression in non-rejected children. In the present studies, relations between proactive aggression and rejection varied. In Study 2, proactive aggression was mainly conducted by rejected children, but in Study 3 proactive aggression occurred as frequently among non-rejected as among rejected children. In some previous studies, proactive aggression in the absence of reactive aggression was not associated with peer rejection according to teachers (Dodge et al., 1997), and even associated with some positively valued characteristics such as leadership and a sense of humor (Dodge \& Coie, 1987). It is unclear whether this is because proactive aggression is not particularly disliked by most peers, or because sociometric dislike nominations of proactively aggressive children by some peers are offset by positive nominations among proactively aggressive friends (Poulin \& Boivin, 2000). If the latter is the case, proactive aggression among non-rejected children may on occasions also occur when overestimation of social competence is disputed by non-friends. More detailed analyses of the exact occasions when overestimation is disputed is - again - required to resolve this issue.

Based on Mead's (1934) 'looking glass self' theory, one would expect that overestimation would diminish over time. This begs the question how consistent overestimation may arise and what maintains it. Is overestimation perhaps supported by parents, a deviant peer group outside the classroom, or a small group of rejected children within the class? A particularly confusing configuration of social sanctioning and disapproval for proactive aggression may occur when it is disliked by many peers, but at the same time believed to contribute to popularity with others by those same peers. Such a discrepancy between actual popularity and perceived popularity may frequently arise for children who proactively use aggression to dominate others (e.g. Cillessen \& Mayeux, 2004; Lease, Kennedy, \& Axelrod, 2002). One may speculate that in those circumstances high perceived popularity reinforces an overly positive perception of one's own social com- petence, despite frequent confrontations with disapproval of such behaviors by peers. To further our understanding of the development of overestimation, it may be particularly interesting to discriminate between aggressive and/or rejected children who keep overestimating over time and children who do not do so. Such analyses may show whether decreases in discrepancies between self-perceived social competence and rejection are accompanied by reductions in different aggressive behaviors. The present studies only addressed peer relations at the sociometric status level and therefore cannot provide answers to these questions. Further studies may use readily available methods to assess friendship characteristics (e.g. Brendgen et al., 2002) and social network positions (e.g. Van Rossem \& Vermande, 2004) of rejected overestimating children to investigate whether some proactively aggressive children maintain relatively high self-perceived social competence either because (a) they are liked by a small subgroup of (equally aggressive?) children or adults (Dishion, Bullock, \& Granic, 2002), (b) they obtain high perceived popularity with it (Lease et al., 2002); (c) they have acquired schemata that impede the accommodation of negative information concerning their own behavior (Lochman \& Lenhart, 1995), or (d) they have a functional need for highly positive self evaluation that prevents a lowering of SPSC (Bushman \& Baumeister, 1998).

We are not sure whether aggressive-rejected children's unrealistically high SPSC scores reflect actual favorable selfevaluations, or only positive self-presentations (Bushman \& Baumeister, 1998). High scores may reflect a successful attempt to show a positive image to the experimenter while filling out a questionnaire. They may even reflect a way for participants to show a positive image to themselves while filling out the questionnaire, even though, with other demand characteristics, they would not actually perceive their own social competence this favorably (see Salmivalli, 2001). Clinicians have suggested that highly aggressive children try to present an image of superiority to others, even though they know "deep inside" that this image is far from realistic. Unfortunately, this hypothesis is hard to falsify, as any failure to demonstrate that aggressive children do not "really" perceive themselves to be very competent may be disregarded as failed assessments of these children's "real" self evaluations. Future research may clarify this issue by studying how selfperceived competence measurements on questionnaires like the SPPC are related to possibly more valid indices of "real" self-perceived competence like disclosure to friends, diaries or trusted adults. An even more promising perspective may be to extend studies of self-perception and self-evaluation beyond a one-dimensional scope on positivity or negativity to more intricate aspects of self-perception, such as defensiveness, vulnerability to negative feedback, and variability (Kernis, 2003; Salmivalli, 2001). 
Strengths, limitations, and conclusions

The present studies are among the first to provide a thorough test of the disputed overestimation hypothesis linking overly positive self-evaluations to aggressive behavior (Baumeister et al., 1996). In doing so, the studies offer several advantages compared to previous work, including both concurrent and longitudinal designs, the use of multiple raters (in Study 3), and the replication of the findings in three independent samples from two continents. Despite these strengths, the present study also has several limitations that need to be taken into account when interpreting the findings. First, the correlational design of the studies does not permit conclusions regarding causal relations. Even though the pattern of relations fits the disputed overestimation hypothesis, it may alternatively be explained by third factors known to be predictive of both rejection, atypical self-evaluation, and aggression. Attention problems, for example, may contribute to both inadequate perception and interpretation of own social competence, to behavior that is rejected by peers, and to a proactively aggressive pursuit of one's own interest whilst paying little attention to peers' concerns. Longitudinal-experimental studies of the effects of interventions in social cognition and peer relations on overestimation and aggression may help clarify the causal nature of the presently established relations.

Second, as in any correlational study, the strength of the established relations depends on the variance observed in the variables included in the analyses. In the general population samples of the three studies, the range of aggressive behaviors included little severe aggression, and mean levels of proactive aggression in Study 3 were especially modest. This limitation is exacerbated by the fact that some children in Study 3 had to be excluded from the analyses because they had not received parental consent to continue their participation at time 2, and these excluded children were less liked by their peers than the final study participants. Moreover, variance in aggression was consistently smaller within the non-rejected groups than in the rejected groups throughout the three studies. As a result, the variance of and the associations between the variables in the statistical analyses were probably smaller than what might be found in less restricted samples, which obviously limits the generalizability of the findings. It should be noted, however, that the variance estimates were not small in absolute terms in the three studies, even for the nonrejected children. As such, it is unlikely that the lack of effect of overestimation on (proactive) aggression found for the nonrejected groups in the present studies is a mere artifact of a lack of variance in these variables in the nonrejected groups. To be sure, replications in larger samples are needed to test whether the disputed overestimation hypothesis indeed exclusively applies to proactively aggressive behavior in rejected children.
Despite these limitations, we believe the present findings are relevant for the ongoing debate on the role of positive self-evaluations in interventions for aggressive behavior problems. Despite strong claims, general advocacy for attempts to either heighten or lower aggressive children's selfregard seem to be misguided in light of the present findings. The relations between self-regard and aggressive behavior found were much more complex than merely 'too high' or 'too low'. At first sight, the term 'overestimation' may seem to suggest that self-regard of rejected-aggressive children was 'too high'. However, although aggression was related to overestimation within the rejected group, mean overestimation was not higher for rejected than for non-rejected children. Apparently aggressive-rejected children do not hold extremely positive views of their social-competence in an absolute sense. Their overestimation is rather due to rejection by peers combined with levels of SPSC comparable to SPSC in non-rejected children than to high SPSC per se. In the absence of evidence for positive effects of interventions that lower or heighten self-regard it may for now be more prudent and promising to focus on the proven effects of increasing children's actual social competence in order to improve social acceptance than to focus on modifying children's self-perception.

\section{References}

Baumeister, R. F., Smart, L., \& Boden, J. M. (1996). Relation of threatened egotism to violence and aggression: The dark side of high self-esteem. Psychological Review, 103, 5-33.

Boivin, M., Vitaro, F., \& Gagnon, C. (1992). A reassessment of the self-perception profile for children: Factor structure, reliability, and convergent validity of a French version among second through sixth grade children. International Journal of Behavioral Development, 15, 275-290.

Brendgen, M., Vitaro, F., Turgeon, L., \& Poulin, F. (2002). Assessing aggressive and depressed children's social relations with classmates and friends: A matter of perspective. Journal of Abnormal Child Psychology, 30, 609-624.

Brendgen, M., Vitaro, F., Turgeon, L., Poulin, F., \& Wanner, B. (2004). Is there a dark side of positive illusions? Overestimation of social competence and subsequent adjustment in aggressive and nonaggressive children. Journal of Abnormal Child Psychology, 32, 305-320.

Bushman, B. J., \& Baumeister, R. F. (1998). Threatened egotism, narcissism, self-esteem, and direct and displaced aggression: Does self-love or self-hate lead to violence? Journal of Personality and Social Psychology, 75, 219-229.

Bushman, B. J., \& Baumeister, R. F. (1999). Threatened egotism, narcissism, self-esteem, and directed and displaced aggression: Does self-love or self-hate lead to violence? Aggressive Behavior, 25, 7-17.

Bushman, B. J., \& Baumeister, R. F. (2002). Does self-love or self-hate lead to violence? Journal of Research in Personality, 36, 543545.

Cillessen, A. H. N., \& Mayeux, L. (2004). From censure to reinforcement: Developmental changes in the association between aggression and social status. Child Development, 75, 147-163. 
Coie, J. D., Dodge, K. A., \& Coppotelli, H. (1982). Dimensions and types of social status: A cross-age perspective. Developmental Psychology, 18, 557-570.

Cole, D. A., Martin, J. M., Peeke, L. A., Seroczynski, A. D., \& Fier, J. (1999). Children's over- and underestimation of academic competence: A longitudinal study of gender differences, depression, and anxiety. Child Development, 70, 459-473.

Cole, D. A., Martin, J. M., Peeke, L. G., Seroczynski, A. D., \& Hoffman, K. (1998). Are cognitive errors of underestimation predictive or reflective of depressive symptoms in children: A longitudinal study. Journal of Abnormal Psychology, 107, 481496.

Crick, N. C., \& Dodge, K. A. (1994). A Review and reformulation of social information-processing mechanisms in children's social adjustment. Psychological Bulletin, 115, 74-101.

Crick, N. C., \& Dodge, K. A. (1996). Social information-processing deficits in reactive and proactive aggression. Child Development, 67, 993-1002.

Cronbach, L. J., \& Furby, L. (1970). How we should measure "change"-or should we? Psychological Bulletin, 74, 68-80.

David, C. F., \& Kistner, J. A. (2000). Do positive self-perceptions have a "dark side"? Examination of the link between perceptual bias and aggression. Journal of Abnormal Child Psychology, 28, $327-$ 337.

Dishion, T. J., Bullock, B. M., \& Granic, I. (2002). Pragmatism in modeling peer influence: Dynamics, outcomes, and change processes. Development and Psychopathology, 14, 969-981.

Dodge, K. A. (1980). Social cognition and children's aggressive behavior. Child Development, 51, 162-170.

Dodge, K. A. (1991). The structure and function of reactive and proactive aggression. In D. Pepler \& K. H. Rubin (Eds.), The development and treatment of childhood aggression (pp. 201-218). Hillsdale: Lawrence Erlbaum.

Dodge, K. A., \& Coie, J. D. (1987). Social-information processing factors in reactive and proactive aggression in children's peer groups. Journal of Personality and Social Psychology, 53, 11461158 .

Dodge, K. A., Lochman, J. E., Harnish, J. D., Bates, J. E., \& Pettit, G. S. (1997). Reactive and proactive aggression in school children and psychiatrically impaired chronically assaultive youth. Journal of Abnormal Psychology, 106, 37-51.

Frijda, N. H. (1986). The emotions. Cambridge: Cambridge University Press.

Harter, S. (1985). The self-perception profile for children: Revision of the perceived competence scale for children. Denver, CO: University of Denver.

Harter, S. (1983). Developmental perspectives on the self-system. In E. M. Hetherington (Ed.), P. H. Mussen (Series Ed.), Handbook of child psychology: Socialization, personality, and social development, vol. 4. New York: Wiley.

Hoffman, K. B., Cole, D. A., Martin, J. M.,Tram, J., \& Seroczynski, A. D. (2000). Are the discrepancies between self- and others' appraisals of competence predictive or reflective of depressive symptoms in children and adolescents: A longitudinal study, part II. Journal of Abnormal Psychology, 109, 651-662.

Holmbeck, G. N. (2002). Post-hoc probing of significant moderational and mediational effects in studies of pediatric populations. Journal of Pediatric Psychology, 27, 87-96.

Hughes, J. N., Cavell, T. A., \& Grossman, P. B. (1997). A positive view of self: Risk or protection for aggressive children? Development and Psychopathology, 9, 75-94.

Hymel, S., Franke, S., \& Freigang, R. (1985). Peer relationships and their dysfunction: Considering the child's perspective. Journal of Social and Clinical Psychology, 3, 405-415.

Kempes, M., Matthys, W., Maassen, G., Van Goozen, S., \& Van Engeland, H. (in press). A parent questionnaire for distin- guishing between reactive and proactive aggression in children European Child \& Adolescent Psychiatry.

Kernis, M. H. (2003). Toward a conceptualization of optimal selfesteem. Psychological Inquiry, 14, 1-26.

Lemerise, E. A., \& Arsenio, W. F. (2000). An integrated model of emotion processes and cognition in social information processing. Child Development, 71, 107-118.

Little, T. D., Henrich, C. C., Jones, S. M., \& Hawley, P. H. (2003). Disentangling the "whys" from the "whats" of aggressive behaviour International Journal of Behavioral Development, 27, 122-133.

Lochman, J. E., \& Dodge, K. A. (1998). Distorted perceptions in dyadic interactions of aggressive and nonaggressive boys: Effects of prior expectations, context, and boys' age. Development \& Psychopathology, 10, 495-512.

Lease, A. M., Kennedy, C. A., \& Axelrod, J. L. (2002). Children's social constructions of popularity. Social Development, 11, 87109.

Lochman, J. E., \& Lenhart, L. (1995). Cognitive behavioral therapy of aggressive children: Effects of schemas. In H. P. J. G. van Bilsen, P. C. Kendall, \& J. H. Slavenburg (Eds.), Behavioral approaches for children and adolescents: Challenges for the next century (pp. 145-166). Plenum Press: New York.

McGrath, E. P., \& Repetti, R. L. (2002). A longitudinal study of children's depressive symptoms, self-perceptions, and cognitive distortions about the self. Journal of Abnormal Psychology, 111, $77-87$.

Mead, G. H. (1934). Mind, self, and society. Chicago: The University of Chicago Press.

Orobio de Castro, B. (2004). Rage and revenge: Social goals in boys with aggressive behavior problems. Paper presented at the XVIIIth Biennial Meetings of the International Society for the Study of Behavioral Development, Ghent, Belgium.

Orobio de Castro, B., Merk, W., Koops, W., Veerman, J. W., \& Bosch, J. D. (2005). Emotions in social information processing and their relations with reactive and proactive aggression in referred aggressive boys. Journal of Clinical Child and Adolescent Psychology, 34, 105-116.

Orobio de Castro, B., Veerman, J. W., Koops, W., Bosch, J. D., \& Monshouwer, H. J. (2002). Hostile attribution of intent and aggressive behavior: a Meta analysis. Child Development, 73, 916934.

Polman, J. D. M., \& Orobio de Castro, B. (2006). A meta-analysis of the distinction between reactive and proactive aggression in children and adolescents. Paper presented at the biennieal meeting of the International Society for Research on Aggression, Minneapolis, U.S.A.

Poulin, F., \& Boivin, M. (2000). The role of proactive and reactive aggression in the formation and development of boys' friendships. Developmental Psychology, 36, 233-240.

Quiggle, N. L., Garber, J., Panak, W. F., \& Dodge, K. A. (1992). Social information processing in aggressive and depressed children. Child Development, 63, 1305-1320.

Salmivalli, C. (2001). Feeling good about oneself, being bad to others? Remarks on self-esteem, hostility, and aggressive behavior. Aggression and Violent Behavior, 6, 375-393.

Taylor, S. E., \& Brown, J. D. (1988). Illusion and well-being: A social psychological perspective on mental health. Psychological Bulletin, 103, 193-210.

Tremblay, R. E., Loeber, R., Gagnon, C., Charlebois, P., Larivee, S., \& Leblanc, M. (1991). Disruptive boys with stable and unstable high fighting behavior patterns during junior elementary-school. Journal of Abnormal Child Psychology, 19, 285-300.

Van Boxtel, H., Orobio de Castro, B., \& Goossens, F. A. (2004). Frequent fighting is related to high self-esteem in rejected children. European Journal of Developmental Psychology, 1, 205214. 
Van Rossem, R., \& Vermande, M. M. (2004). Classroom roles and school adjustment. Social Psychology Quarterly, 67, 396411.

Veerman J. W., Straathof, M. A. E., Treffers, P. D. A., Van Den Bergh, B. R. H., \& Ten Brink, L. T. (1987). Competentiebelevingsschaal han- dleiding [Self-Perceived Competence Scale: Test manual]. Lisse: Swets \& Zeitlinger.

Vitaro, F., Brendgen, M., \& Tremblay, R. E. (2002). Reactive and proactive aggression: Antecedent and subsequent correlates. Journal of Child Psychology and Psychiatry, 43, 495-505. 